\title{
Cross-Section of Asset Returns: Emerging Markets and Market Integration
}

\author{
Tamara Ajrapetova*
}

\begin{abstract}
:
Asset pricing in its essence is a very controversial topic. Despite numerous research papers criticising traditional approaches, such as linear factor models, practitioners as well as academics repeatedly return to the milestone models such as the Capital Asset Pricing Model (CAPM), mainly due to their attractive simplicity. This article focuses on the risk-return relationship by comparing the power of traditional and alternative asset pricing models in explaining the cross-section of asset returns. The focus is on unconditional models, commonly used among investors and equity analysts. This paper is based on the research performed by Estrada in 2004 and it extends his approach by introducing the use of GMM. The results suggest that for Emerging markets' investors should give preference to total risk measures over systematic risk measures. Within the category of systematic risk measures, downside beta proved its superiority to traditional CAPM beta. The results can be attributed to delayed integration process, partially justified by the lower FDI and portfolio investments into Emerging markets.
\end{abstract}

Key words: Asset Pricing; CAPM; Downside Risk Models.

JEL classification: G11, G12, G15, G31.

\section{Introduction}

Asset pricing is one of the most crucial areas in finance, covering not only the issue of pricing securities, but also company or investment valuation issues along with capital structure formation. It is therefore not surprising that this field received extensive attention in academic literature. However, despite the vast research base, the consensus has not yet been reached, especially when it comes to the treatment of Emerging markets ("EMs" from hereafter). Over the past 20 years, EMs have gained extreme importance in international financial markets and have become one of the areas where new opportunities are found. With the GDP and productivity growth slowing down in Developed markets ("DMs" from hereafter), EMs are commonly viewed as places for positive future economic prospects. This shift in economic performance has drawn attention to pricing of securities in less liquid, less transparent and more shock-prone markets.

\footnotetext{
Tamara Ajrapetova; University of Economics in Prague, Faculty of Finance and Accounting, Department of Banking and Insurance, W. Churchill Sq. 4, 13067 Prague, Czech Republic, <ayrt00@vse.cz>.

This research has been supported by the Czech Science Foundation Grant P402/12/G097 Dynamical Models in Economics and by the internal VŠE grant Advanced methods of financial asset returns and risks modelling IGA VŠE F1/23/2015.
} 
Over the past four decades, there was and remains a stable trend of applying the model which Sharpe (1964) and Lintner (1965) suggested as the key model for DMs valuations. CAPM is a very attractive model, firstly due to its simplicity and secondly due to the way it builds a relationship between the risk and expected returns, which itself is quite intuitive. However, as for any model, its assumptions limit the application only to a certain spectrum of problems. It is a stylized fact that EMs exhibit nonstandard stock behaviour, with extreme volatility (volatility clustering), nonmorality in the return distribution and fat tails. Thus, the main question we are trying to answer in this article is related to the reliability and applicability of the CAPM model to the settings of EMs. As an alternative to traditional CAPM model, this research paper tests the downside risk measures, and more specifically the D-CAPM. This is done through the comparison of statistical performance of the two kinds of risk variables: (1) total risk variables (standard deviation and semistandard deviation) and (2) systematic risk variables (beta and downside beta). The ultimate goals is to specify which models are more reliable for stock valuation and portfolio optimization in EMs.

The presented article can be considered as an extension of the research performed by Javier Estrada over several years since 2000-2005. We are using the same MSCI indices, though extending the time horizon to cover the financial crisis of 2007-2008 and the recovery (from 01/01/2000 to 31/12/2016). Furthermore, in contrast to the Estrada's approach, we implement GMM instead of OLS to adjust for heteroscedasticity in error terms. The paper is organized as follows. The first chapter focuses on the history of evolution of asset pricing models. Building on the comprehensive overview, it then moves on to methods used in testing the risk measures and data specification. In the last section, the results are presented with a discussion on whether these trends can be seen to continue. The main finding of this article confirms the key trends in the literature with the preference given to downside-risk measures. Nevertheless, in contrast to the past research our findings suggest priority of total risk measures over systematic risk measures. We attribute this result to the slower than expected integration of Emerging markets into the world markets.

\section{CAPM Evolvement}

There is quite an extensive body of literature that deals with testing of the CAPM model, especially in the DMs. The first tests were performed in early 1970s. During this time, the model was gaining on popularity and majority of the research done offered evidence in favour of the CAPM model. The most influential studies of that period that are still widely referenced include Black, Jensen and Scholes (1972), Fama and MacBeth (1973) and Blume and Friend (1973). As more research was done, the initial success of CAPM has during the 1970s quickly eroded. We can identify several perspectives on problematics of CAPM in the 
literature. The first perspective important to mention has to do with the rejection of CAPM overall as a reasonable model. Ross (1977) and Roll (1977) were the first to take this point. They claimed that there is evidence that indices are not efficient portfolios and they thus exhibit deviations from efficiency that can bias the riskreturn relationship. Since the true market portfolio is unobservable, the CAPM model consequently cannot be empirically used. Although many professionals and academics did not support this perspective, its only alternative in the form of Arbitrage Pricing Theory has not proven reliable in testing. The issue of using indices as proxies for the market portfolio remains unsolved.

The second perspective expresses a greater loyalty to the fundamentals of the CAPM model. However, it still admits that there are certain anomalies that require necessary adjustments. The most common adjustments under this perspective are additional factors that created a new notion of the so-called multifactor CAPM. Fama and French (1992) published the most influential paper under this classification. As opposed to the traditional CAPM, their findings have shown that beta is not the only measure of risk and there are Size, Value and Momentum effects. These findings were also supported by the previous research of Black, Jensen and Scholes (1972), Miller and Scholes (1972) and were further confirmed by the research done by Reinganum (1981), Banz (1985), Stattman (1980) etc. The majority of papers under this classification fall under the domain of fundamental models.

The last perspective, and the one which was implemented in this research paper, attempts to fix the theoretical flows of the CAPM model, primarily related to its statistical properties. In this case, we no longer consider extra factors (multifactor CAPM), but rather modified-CAPM (Abbas, Ayub, Sargana and Saeed 2011, p. 192). Under this classification, academicians were trying to address issues such as non-zero intercept, asymmetric distribution of returns (normality condition), beta estimation bias or CAPM without risk-free borrowing. This article focuses on the issues of asymmetric distribution as well as limitations associated with the investor preferences that CAPM model inherited from Expected Utility Theory. These limitations evoked a discussion within the academic community on whether there are better measures of risk, such as e.g. downside volatility and measures related to these models.

Kahneman and Tversky (1979), Gul (1991) and Estrada (2000, 2002, and 2007) conclude that investors do not give equal weights to downside and upside movements in the returns. Brooks and Galagedera (2010, p.5) argue that this is especially true for EMs, where given identical regulatory and tax environments the loss of the utility caused by the loss of one dollar is much higher than the utility of gaining one dollar, due to the lower average wealth. Based on the MVB and the CAPM model, marginal utility of receiving an extra dollar and losing an extra 
dollar is the same. Thus, the problem of the CAPM theory lies in the way it defines utility that investors receive from their consumption.

\section{Downside Risk Measures}

Downside risk measures have been neglected for a long time and started gaining in popularity just over the last 10 years, specifically following the 2007-2008 crisis when the issues of asymmetric distributions and extreme events were identified not only in asset pricing but also in credit risk. Despite the relatively recent pick in the attention, the first influential work in this direction has been written already in 1952 by Roy, who suggested choosing portfolios based on the probability that its return will exceed a certain threshold. Markowitz (1959) has also considered the downside risk in his seminal work, highlighting that semivariance produces more efficient portfolios than standard deviation. Nevertheless, traditional risk measures were chosen due to the computational complexity.

In 1960s, the first testing of downside risk measures focused on the superiority of semivariance over standard variance. However, at that time there was limited applicability of these findings as there was no method to quantify the stochastic dominance, which was one of the main tools used to measure semivariance. Later in 1970s, when Bawa (1975) generalized the semivariance risk measure with his Lower Partial Moment (LPM) theory and then Fishburn (1977) extended this research to incorporate all the types of investors (risk averse, risk seeking and risk neutral), integration of downside risk into the CAPM became possible.

The most influential contributions in this area include Hogan and Warren (1974), Bawa and Lindenberg (1977), Harlow and Rao (1989), Estrada (2002) and Estrada and Serra (2005). Despite of this, the one key theme that all these papers have in common, definition of the downside risk, varies considerably. The first model suggested by Hogan and Warren (1974) called the E-S model, gave preference to semideviation over standard deviation, offering the following definition of downside beta:

$$
\beta_{H W}=\frac{E\left[\left(R_{i}-R_{f}\right) * \min \left(R_{m}-R_{f}, 0\right)\right]}{E\left[\min \left(R_{m}-R_{f}, 0\right)\right]^{2}} .
$$

Where $R_{i}, R_{f}$ and $R_{m}$ stand for return on security, risk-free asset and market asset, respectively. In this equation, we can see the same logic as in the traditional CAPM with the exception of taking the minimum of either the excess market return or zero. Under this model, a security would add to the risk of a portfolio only if it's and market's returns fell below the risk-free rate. Whereas, if security returns were above the risk-free rate and only the market returns would fall short, it would reduce the amount of risk the security adds to the portfolio. Bawa and Lindenberg (1977), who have generalized this approach in their Mean-Lower 
Partial Moment (MLPM) model has kept this definition of semideviation and downside beta, whereas Harlow and Rao (1989) suggest replacing the risk-free rate with mean return yielding the following alternative:

$$
\beta_{H R}=\frac{E\left[\left(R_{i}-\mu_{i}\right) * \min \left(R_{m}-\mu_{m}, 0\right)\right]}{E\left[\min \left(R_{m}-\mu_{m}, 0\right)\right]^{2}} .
$$

Where $\mu_{i}$ and $\mu_{m}$ are security and market average returns, respectively.

The most recent research in this area, and the one adopted in this paper, has been first proposed by Estrada in 2000. Estrada has offered a new definition of semivariance and downside beta, where security adds a risk to the portfolio only when both the security and the market fall below their thresholds given by the mean return, with respect to each relevant distribution.

$$
\beta_{E}=\frac{E\left[\min \left(R_{i}-\mu_{i}, 0\right) * \min \left(R_{m}-\mu_{m}, 0\right)\right]}{E\left[\min \left(R_{m}-\mu_{m}, 0\right)\right]^{2}} .
$$

The key empirical studies testing this model are Estrada $(2000,2002)$ and Estrada and Serra (2005). Generally, testing in the EMs is laboured by limited data availability and relative illiquidity of the markets, where sometimes only several firms are traded at the relevant Stock Exchange regularly (e.g. Croatia and Slovenia). The main hypothesis is that EMs still lack integration into the global market, thus it is not so evident if downside beta should be preferred over total risk measures. Therefore, one of the key questions is not only whether downside beta outperforms the traditional CAPM beta, but also whether it is more efficient than semideviation.

\section{Data and Methodology}

This study encompasses countries that accelerated in their growth in the past 10-15 years. In this case important criteria for selection were increased FDI into the county of choice and increasing liquidity of the market under consideration. Overall, the research covers 27 countries listed in Table A.1. In order to make a comparison, we have also performed the same kind of analysis on the DMs (see Table A.2). Overall, this is the same set of countries as in the research done by Estrada in 2002. In order to maintain comparability of the results with the previous research, we adopted MSCI Gross Return, capitalization-weighted indices quoted in US dollars.

The data were collected on monthly basis for the period starting from 01/01/2000 and ending on 31/12/2016, and they include both capital gains and dividends. To our knowledge, all the previous studies covering the same models and country spectrum were limited to the year 2004, i.e. do not encompass the sub-mortgage crisis of 2007-2008, itself an important milestone for testing. 
Ajrapetova, T.: Cross-section of asset returns: Emerging Markets and Market Integration.

\subsection{Traditional and Downside Beta Coefficients}

Traditional beta is the most widely calculated parameter in asset pricing. It is used not only in portfolio management, but also in company, stock and even project valuations. In this paper, estimation of the beta coefficient was done numerically, through calculation of the correlation coefficient and respective standard deviations of MSCI World index and each respective country index.

The general formula has been followed:

$$
\begin{gathered}
\beta_{i}=\frac{\sigma_{i M}}{\sigma_{i} * \sigma_{M}} * \frac{\sigma_{i}}{\sigma_{M}}=\rho_{i M} * \frac{\sigma_{i}}{\sigma_{M}}, \\
\sigma_{i}=\sqrt{E\left[\left(R_{i}-\mu_{i}\right)^{2}\right]} .
\end{gathered}
$$

The calculation of downside risk measures is majorly influenced by the set benchmark with respect to which one calculates negative volatility. Furthermore, to be more precise, practitioners should decide if this concept is applied only to the security returns or also to the market portfolio. As seen above, the first definition of downside beta has been given Hogan and Warren (1974), suggesting the calculation of downside movements only for the market, often such approaches are referred to as one-sided.

$$
\beta_{i, H W}^{-}=\frac{\sum_{t=1}^{T}\left[\left(R_{i t}-R_{t}\right) * \min \left\{\left(R_{m t}-R_{t}\right), 0\right\}\right]}{\sum_{t=1}^{T}\left[\min \left\{\left(R_{m}-R_{t}\right), 0\right\}\right]^{2}} .
$$

If we consider the above-mentioned Estrada's specifications of downside beta, we will be confronted with minimization of both the returns of assets and returns of the market, so-called two-sided measures. We will adopt Estrada's $\beta_{E}$, which can be derived through the following logical steps.

$$
\text { If } R_{i t}-E\left(R_{i}\right)=\left[\min \left(R_{i t}-E\left(R_{i}\right), 0\right)+\max \left(\left(R_{i t}-E\left(R_{i}\right), 0\right)\right]\right] .
$$

We can then obtain:

$\min \left(R_{i t}-E\left(R_{i}\right), 0\right)+\max \left(\left(R_{i t}-E\left(R_{i}\right), 0\right)=b_{i 2} \min \left(R_{m t}-E\left(R_{m}\right), 0\right)+\right.$ $+\max \left(\left(R_{m t}-E\left(R_{m}\right), 0\right)+\varepsilon_{i t}\right.$

Multiplying both sides by $\min \left(R_{m t}-E\left(R_{m}\right), 0\right)$ and taking expectation we get, $E\left[\min \left(R_{i t}-E\left(R_{i}\right), 0\right) \min \left(R_{m t}-E\left(R_{m}\right), 0\right)\right]+\mathrm{E}\left[\max \left(R_{i t}-\right.\right.$ $\left.-E\left(R_{i}\right), 0\right) \min \left(R_{m t}-E\left(R_{m}\right), 0\right)=b_{i 2} \mathrm{E}\left[\min \left(R_{m t}-E\left(R_{m}\right), 0\right)\right]^{2}$ which reduces to

$$
\begin{aligned}
\beta_{i}^{D} & =b_{i 2}-\frac{E\left[\max \left\{\left(R_{i}-\mu_{i}\right), 0\right\} * \min \left\{\left(R_{m}-\mu_{m}\right), 0\right\}\right]}{E\left[\min \left\{\left(R_{m}-\mu_{m}\right), 0\right\}\right]^{2}} \\
& =\frac{E\left[\min \left\{\left(R_{i}-\mu_{i}\right), 0\right\} * \min \left\{\left(R_{m}-\mu_{m}\right), 0\right\}\right]}{E\left[\min \left\{\left(R_{m}-\mu_{m}\right), 0\right\}\right]^{2}} .
\end{aligned}
$$


Where: $R_{i}$ - return on the asset; $R_{m}$ - Return on the market portfolio; $b_{i 2}-C A P M$ beta; $\mu_{m}$ - average return of the market; $\mu_{i}-$ average return of the portfolio.

The definitions above are based on the following definitions of semideviation and co-semivariance:

$$
\begin{gathered}
\sum_{i}=\sqrt{E\left[\min \left\{\left(R_{i}-\mu_{i}\right), 0\right\}^{2}\right]}, \\
\sum_{i m}=E\left[\min \left\{\left(R_{i}-\mu_{i}\right), 0\right\} * \min \left\{\left(R_{m}-\mu_{m}\right), 0\right\}\right] .
\end{gathered}
$$

It can be seen from these equations that there is a difference between the CAPM beta and the Estrada's beta, only when the asset shows upward movement, whereas the market is down. It is important to highlight that currently there is no agreement in the literature as to which of the definitions is more precise.

\subsection{Methods of Statistical Analysis}

Statistical analyses were performed with the use of correlation matrixes and crosssectional regression. Cross-sectional regression in this case refers to simple linear second order regression of the type:

$$
y_{i}=\gamma_{0}+\gamma_{1} x_{i}+u_{i} .
$$

Where $y_{i}$ is mean return and $x_{i}$ is the risk variable and $u_{i}$ is an error term. Similarly to previous research $x_{i}$ represent different risk variables such as:

- Beta (measure of systematic risk)

- Standard deviation (measure of total risk)

- Semi-standard deviation (measure of total downside risk)

- Downside Beta (measure of downside risk)

The choice of risk variables was determined by their differing performance on the same markets. Beta was chosen as the most common measure of systematic risk in DMs. Standard deviation was selected due to its stronger performance in partially integrated markets, whereas downside risk measures were chosen as an alternative to the above-mentioned tools.

The above-specified classical linear regression is just a specification of the form in which the regression will be done. However, another more important question is the method used to estimate the parameters. The most widely used options are either Ordinary Least Squared method ("OLS") or the General Least Squares. When it comes to OLS, the method yields unbiased and efficient estimates only in case certain conditions are met. These conditions are related to properties of the error process that in literature are commonly referred to as "Weak set of assumptions" and implicitly suggest that OLS is optimal only when the error term is generated by an independent and identically distributed process. 
It is a stylized fact that in case of EMs, the above specified conditions do not on average hold for the distributions of returns as they exhibit volatility clustering and fat tails. Therefore, in this paper preference will be given to GMM (Generalized Method of Moments.) GMM was introduced by Hansen (1982) and it is particularly useful for scenarios when full shape of distribution is not defined or when the researcher does not want to impose assumptions on the distribution. The preference of GMM over OLS can be attributed to endogeneity problem that occurs due to correlation of explanatory variable with an error term. This can be a result of a number of issues such as (1) autoregression and autocorrelation of error terms or (2) rather common correlation between independent and depend variables and (3) conditional heteroscedasticity. In the CAPM model, the explanatory variable of excess market returns can be well correlated with the excess returns of the security or a portfolio. GMM is the only estimation method that allows dealing with this problem. Similarly to the study by Tahir, Abbas, Sargana, Ayub and Saeed (2013, p. 125), for the first step regression we use the Newey-West estimator adjusted GMM, which will ensure parameter robustness corrected for heteroscedasticity and autocorrelation, whereas for cross-sectional regression White's estimator will be implemented to ensure t-test statistics robustness.

\section{Empirical Results}

In Table (A.1) one can find the arithmetic mean returns, traditional beta, standard deviations, semideviations and finally the downside beta of EMs. Given parameters can by assigned to the models specified below.

$$
\begin{gathered}
E\left(R_{p}\right)=R_{f}+\frac{\sigma_{i}}{\sigma_{M}}\left(R_{M}-R_{f}\right), \\
E\left(R_{p}\right)=R_{f}+\frac{\sum_{i}}{\sum M}\left(R_{M}-R_{f}\right), \\
E\left(R_{p}\right)=R_{f}+\beta\left(R_{M}-R_{f}\right), \\
E\left(R_{p}\right)=R_{f}+\beta^{D}\left(R_{M}-R_{f}\right) .
\end{gathered}
$$

Models 12 and 13 are total risk models, whereas 14 and 15 are systematic risk models. Total risk models determine the risk premium based on the ratio of standard deviation of the portfolio to standard deviation of the market or semideviation when it comes to downside risk measures. As a result, those models assume that the correlation between the portfolio and the market is equal to one. This implies we also price the diversifiable risk which according to the Markowitz Modern Portfolio Theory should not be priced in fully integrated markets. It follows that general systemic risk measures, such as CAPM, should perform better in fully integrated markets, whereas total risk measures should be preferred when it comes to segmented markets. 
Before taking a look at the risk-return relationship from cross-sectional regression perspective, it is always useful to consider descriptive statistics and examine if there are any outliers. Looking at the correlation between mean returns and the four risk measures, all the parameters except for beta are significant at the 0.01 level, which indicates lower chances of the Type I error (see Table A.3 in Appendix). The results, though, are quite different from the previous research. The strongest association can be seen between mean returns and standard deviation, followed by semideviation and then downside beta (see Table A.3 in Appendix). However, it is important to note that the difference between the two is negligible. Another crucial relationship is the correlation between standard deviation and semideviation (0.953), this relationship suggests that the association of total risk measure (standard deviation) with the mean returns goes largely through the downside risk. This confirms the previous findings of Estrada (2000).

Downside beta is the third strongest measure of association, whereas the relationship between mean returns and traditional beta shows no association. Estrada (2000, p. 22) received similar results in his first paper. However, this is quite a different outcome to his more recent papers published in 2005. Majority of previous literature suggests using systematic downside risk measures and outlines their priority over total risk measures. One of the main arguments in favour of such a choice is so-called "contagion effect" stating that markets are more integrated on the downside than on the upside. This effect is particularly visible during the times of crisis, when the markets become more correlated.

\section{Tab. 1 Cross-Sectional Regression Results EMs}

\begin{tabular}{|c|c|c|c|c|}
\hline Eq Name & \multicolumn{4}{|c|}{ MEAN RETURNS } \\
\hline \multirow{2}{*}{ GAMMA(0) } & -0.002913 & 0.0104820 & -0.002943 & -0.003065 \\
\hline & {$[-0.947]$} & {$[5.118]^{* *}$} & {$[-0.995]$} & [-0.929] \\
\hline \multirow{2}{*}{ STD } & 0.007548 & & & \\
\hline & {$[4.627]^{* * *}$} & & & \\
\hline \multirow{2}{*}{ BETA } & & 0.0001529 & & \\
\hline & & [0.081] & & \\
\hline \multirow{2}{*}{ SEMIDEVIATION } & & & 0.008335 & \\
\hline & & & {$[4.701]^{* * *}$} & \\
\hline \multirow{2}{*}{ DOWNSIDE_BETA } & & & & 0.015318 \\
\hline & & & & {$[4.354]^{*}$} \\
\hline R-squared & 0.4821 & 0.0003 & 0.5011 & 0.4519 \\
\hline
\end{tabular}

Source: Eikon + author's computations. 
Looking at the results of cross-sectional regressions (see Table 1); firstly it is important to highlight that there was one outlier (Colombia), which we excluded from the testing. The highest coefficient of determination (R-squared) is assigned to semideviation, where approximately $50.11 \%$ of variations in mean returns are explained by the risk measure. The second highest coefficient of determination belongs to standard deviation that explains $48.21 \%$ of variations, followed by downside beta explaining $45.19 \%$. In our estimates beta coefficient is statistically insignificant according to the t-statistics and the CAPM model has R-squared of zero, which confirms the previous findings of Harvey (1995). Furthermore, according to the theory the constant in the cross-sectional regression, in other words the zero-beta excess return, should be equal to zero (Cochrane 2001, p. 236). Whereas our intercept (Gamma(0)) is statistically different from zero (Table 1 ), meaning that zero-beta securities receive some excess return, even though they do not bear any extra risk.

If we compare these results to the ones received previously by Estrada (2005), the main difference lies in the strength of semideviation, which in contrast to the previous research has now stronger explanatory power than downside beta. Based on the findings above, one can argue that investors should give preference to the following models instead of the classical CAPM and D-CAPM:

$$
\begin{gathered}
E\left(R_{p}\right)=R_{f}+\frac{\Sigma_{p}}{\Sigma_{M}}\left(R_{M}-R_{f}\right), \\
\text { or } \\
E\left(R_{p}\right)=R_{f}+\frac{\sigma_{p}}{\sigma_{M}}\left(R_{M}-R_{f}\right) .
\end{gathered}
$$

The superiority of total risk measures over systematic risk measures can be justified by an assumption that the markets are segmented, which contradicts a common view that EMs are partially integrated. The main argument why standard deviation and semideviation are more efficient in the case of segmented markets is the fact that some firm-specific risk is non-diversifiable and thus investors are supposed to be compensated for it with the risk premium. This extra risk is not accounted for by systematic risk measures. Furthermore, in the case of country indices, one can argue that there is also a non-diversifiable country risk that should also be taken into account.

One of the possible triggers of slower integration of the financial markets are the subprime-mortgage crises that were experienced by financial markets in 20072008, resulted in financial distress and were not covered by studies such as those by Estrada (2002; 2005). Particularly, this could be reasoned with less investment coming from advanced economies into EMs. IMF (2016) reported the peak of net capital flows into EMs in 2010; however, since then there has been a steady slowdown connected to the monetary policy in the US and the EU that from that 
moment implemented Quantitative Easing programmes and focused on boosting growth locally. In case of the EU, stimulus programmes still continue. Furthermore, there was a change in the market sentiment and in general, IMF (2017) reported an increase in global risk aversion. Following the crisis, the regulators have also imposed tighter regulation on large institutional investors that started suffering from extra charges connected to non-investment grade securities. Thus, not only FDI investments have suffered declines, but also portfolio investments. All of this contributed to the trends in reversion of the integration process.

Of course, concept of integration is a controversial topic. A broad base of literature focuses on the studies of market integration, however there is not one given definition. Among the most well-known are correlations between country indices, $\mathrm{R}$-squared of the regressions, factor models based on economic fundamentals and more unique approaches that take into account yields of sectors. The key contributors to the literature base are Bekaert and Harvey (1995), Dumas, Harvey, and Ruiz (2003); Bekaert, Harvey, Lundblad, and Siegel (2008); and Pukthuanthing and Roll (2009). Despite, the differences in the approaches taken, all of them agree that EMs still lack financial integration and this paper confirms this finding.

\section{Fig. 1 Net Capital Inflows into Emerging Markets as \% of GDP}

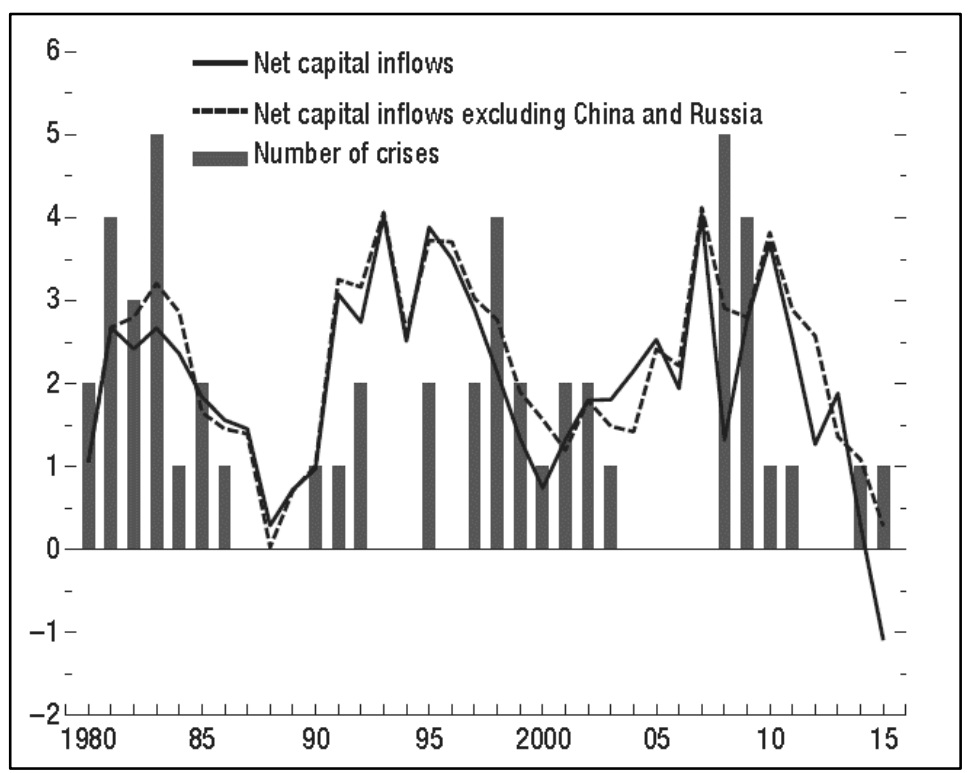




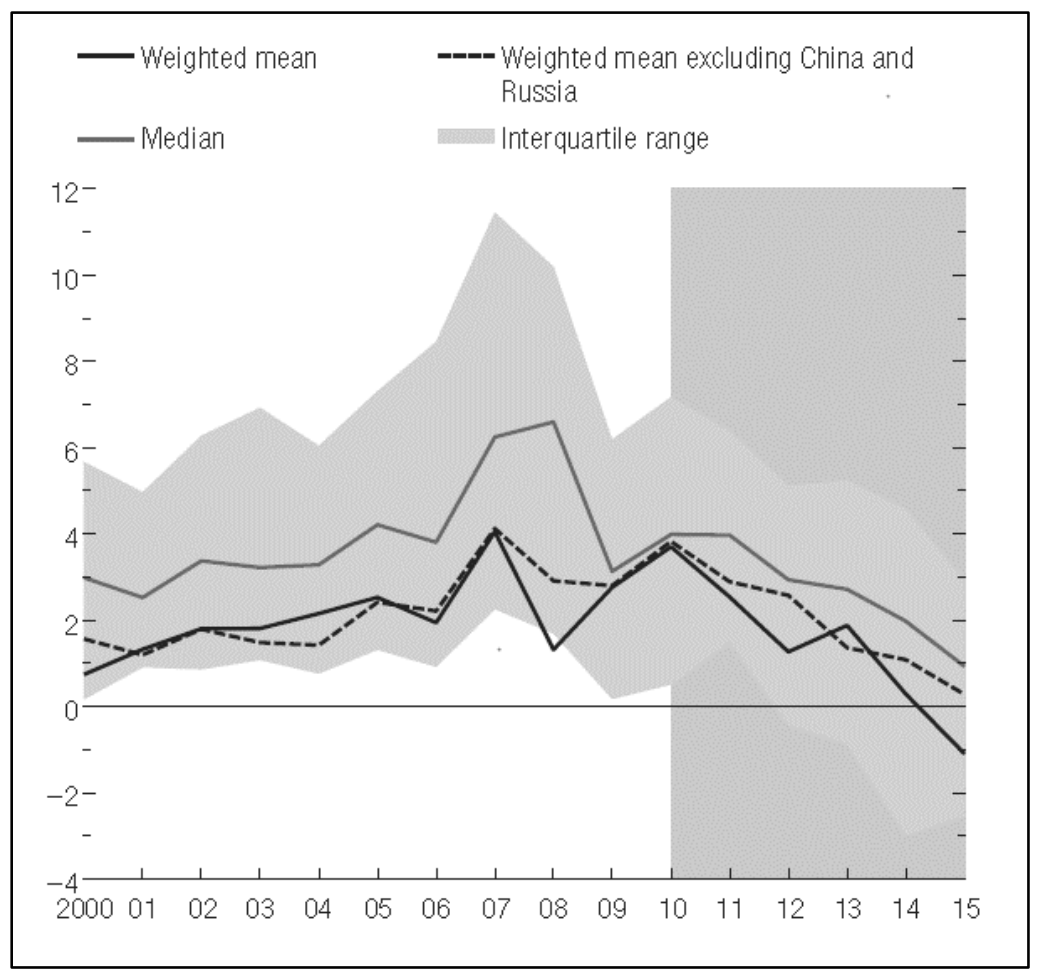

Source: IMF (2016, p. 64, 66), Understand the Slowdown of Capital Flows into Emerging Markets, Chapter.

To further prove the above statement it is necessary to consider DMs that are generally considered by researchers as fully integrated into the global financial markets. Thus, the CAPM model and traditional risk measures should show higher explanatory power for the mean returns than in the case of EMs. The results for the four calculated risk measures can be found in Table 2.A in the appendix.

Cross-sectional regression has shown that the relationship between beta and returns is positive as argued by the model. Opposed to EMs, the largest R-squared is attributed to downside beta, explaining approximately $16 \%$ of the variation in the mean returns, followed by semideviation and then traditional beta. This suggests that downside risk measures are superior to traditional risk measures in fully integrated markets, but in this case beta still showed some explanatory power and alpha coefficient was not statically different from zero. Thus, traditional CAPM does hold in DMs, but D-CAPM is more efficient. 


\section{Tab. 2 Cross-Sectional Regression Results DMs}

\begin{tabular}{|c|c|c|c|c|}
\hline $\begin{array}{l}\text { Eq Name } \\
\text { Dep. Var }\end{array}$ & \multicolumn{4}{|c|}{ MEAN RETURN } \\
\hline GAMMA(0) & $\begin{array}{r}0.151323 \\
{[0.7345]} \\
\end{array}$ & $\begin{array}{r}0.308653 \\
{[1.8839]}\end{array}$ & $\begin{array}{r}0.194240 \\
{[1.0755]}\end{array}$ & $\begin{array}{r}0.006971 \\
{[0.0272]}\end{array}$ \\
\hline BETA & $\begin{array}{r}0.397052 \\
{[2.3527]^{*}}\end{array}$ & & & \\
\hline $\begin{array}{l}\text { STANDARD_DEVI } \\
\text { ATION }\end{array}$ & & $\begin{array}{r}4.749568 \\
{[1.9053]} \\
\end{array}$ & & \\
\hline SEMIDEVIATION & & & $\begin{array}{r}9.058340 \\
{[2.4603]^{*}} \\
\end{array}$ & \\
\hline DOWNSIDE_BETA & & & & $\begin{array}{r}0.711021 \\
{[2.4738]^{*}} \\
\end{array}$ \\
\hline R-squared & 0.1008 & 0.0515 & 0.1047 & 0.1634 \\
\hline
\end{tabular}

Source: Eikon + author's computations.

One can also observe rather low values of the coefficients of determination for all the tested models. This phenomenon has also been encountered by Estrada (2005, pp. 178-179), however justification of such results is not clear. One can attribute this to the distribution of mean returns within the sample, which in comparison to EMs showed higher dispersion (see Figure 2), suggesting possible deviations from normality. This in turn can be ascribed to different market triggers that drive development of the indices representing the countries, as the set includes quite distinctive countries in terms macro and company fundamentals. 


\section{Fig. 2 Distribution of Mean Returns}

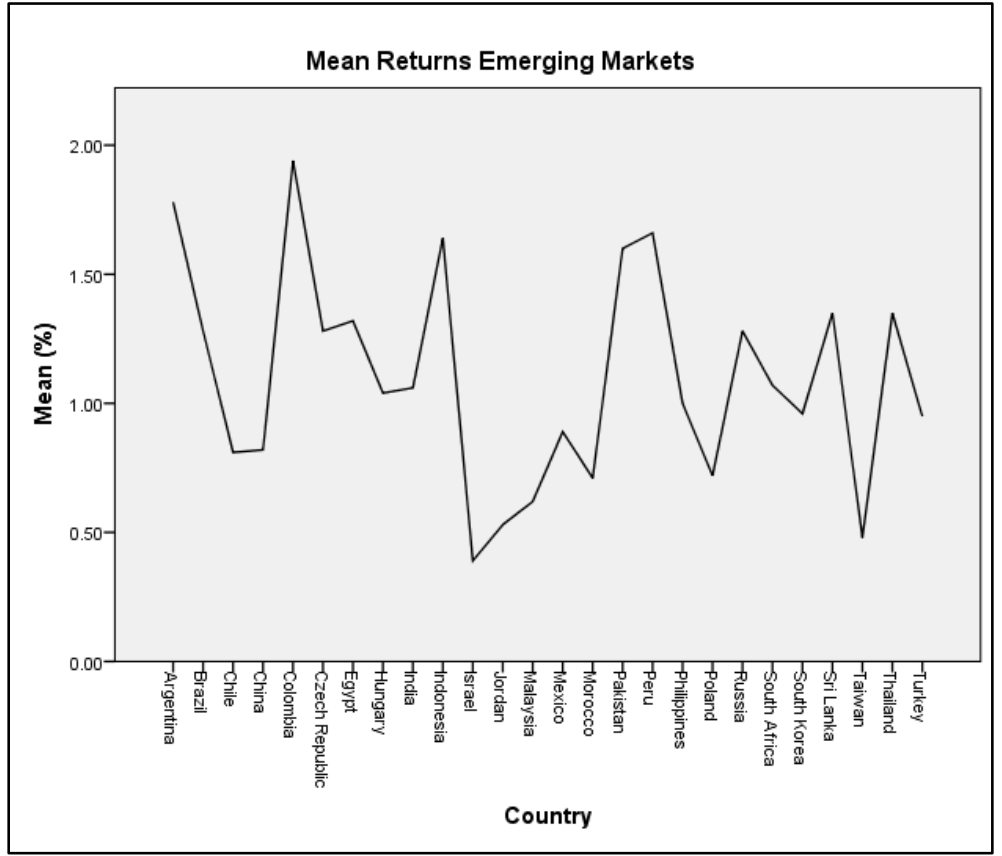

Source: Eikon + author's computations.

\section{Conclusions and Remarks}

Growing interest of investors in EMs raises an important discussion about pricing of risk in these regions. It is crucial to highlight that markets falling under this umbrella term, have diverging trends and often cannot be viewed as a homogenous set. One of the key questions that practitioners have to answer is what model to use in case of company valuations, project valuation or portfolio investment decisions. This article attempted to answer this question through the lenses of cross-section analysis performed with the use of statistical tools. The research focused on less advanced models that are widely used for stock valuations and portfolio optimization in corporate world.

Explanatory power of traditional beta has proven to be insignificant in case of EMs, however performed quite well in DMs relative to other risk measures. Downside beta outperformed traditional beta in the case of DMs and showed the best results in comparison to other risk measures. This, however, was not the case with respect to EMs, where total risk measures performed the best. This implies that in Ems, the diversifiable risk should still be priced in. This phenomenon can be attributed to slower integration into financial markets, triggered by lower net inflow of FDI into the region from the part of DMs over the period. One can 
expect this trend to continue until DMs recover from the crisis of 2007-2008 and exit from their Quantitative Easing programs. Another important factor contributing to the issue was a change in investor sentiment and tightening of regulation that constrained institutional investors to invest only limited portion of their funds to non-investment grade high-yield securities that are also less liquid. Thus, when performing valuations for EMs we would suggest using total risk measures with preference given to semideviation.

\section{References}

Abbas, Q., Ayub, U., Saeed, S., 2011. CAPM - Exclusive Problems Exclusively Dealt, Interdisciplinary Journal of Contemporary Research on Business 2, 947955.

Bawa, V., 1975. Optimal rules for ordering uncertain prospects, Journal of Financial Economics 1, 95-121. DOI: 10.1016/0304-405x(75)90025-2.

Bawa, V., Lindenberg, E., 1977. Capital market equilibrium in a mean-lower partial moment framework, Journal of Financial Economics 2, 189-200. DOI: 10.1016/0304-405x(77)90017-4.

Bekaert, G., Harvey, C., 1995. Time-Varying World Market Integration, The Journal of Finance 2, 403-444. DOI: 10.1111/j.1540-6261.1995.tb04790.x.

Bekaert, G., Harvey, C., Lundblad, C., Siegel, S., 2008. What Segments Equity Markets, Review of Financial Studies 12, 3841-3890. DOI: 10.1093/rfs/hhr082.

Black, F., 1972. Capital market equilibrium with restricted borrowing, The Journal of Business 3, 444-455. DOI: 10.1086/295472.

Black, F., Jensen, Scholes, M., 1972. The capital asset pricing model: Some empirical tests, Studies in the theory of capital markets, 79-121. Praeger, New York.

Blume, M., Friend, I., 1973. A New Look at the Capital Asset Pricing Model, Journal of Finance 1, 19-33. DOI: 10.2307/2978165.

Cochrane, J., 2001. Asset Pricing. $1^{\text {st }}$ edn. Princeton University Press, New Jersey.

Dumas, B., Harvey, C., Ruiz, P., 2003. Are correlations of stock returns justified by subsequent changes in national outputs? Journal of International Money and Finance 6, 777-811. DOI: 10.1016/j.jimonfin.2003.08.005.

Estrada, J., 2002. Systematic risk in emerging markets: the D-CAPM, Emerging Markets Review 4, 365-379. DOI: 10.1016/s1566-0141(02)00042-0.

Estrada, J., 2004. The cost of equity of Internet stocks: a downside risk approach, The European Journal of Finance 4, 239-254. DOI: 10.1080/1351847032000137429. 
Estrada, J., Serra, A., 2005. Risk and return in emerging markets: Family matters, Journal of Multinational Financial Management 3, 257-272. DOI: 10.1016/j.mulfin.2004.09.002.

Fama, E., French, K., 1992. The cross section of expected return, The Journal of Finance 2, 427-465. DOI: 10.2307/2329112.

Fama, E., MacBeth, J., 1973. Risk, return and equilibrium: empirical tests, Journal of Political Economy 3, 607-636. DOI: 10.1086/260061.

Fishburn, P., 1977. Mean-Risk Analysis with Risk Associated with Below-Target Returns, American Economic Review 2, 116-126.

Gul, F., 1991. A Theory of Disappointment Aversion, Econometrica 3, 667-686. DOI: $10.2307 / 2938223$.

Harlow, W., Rao, R., 1989. Asset Pricing in Generalized Mean-Lower Partial Moment Framework: Theory and Evidence, Journal of Financial and Quantitative Analysis 3, 288-311.

Harvey, C., 1995. Predictable risk and returns in emerging markets, Review of Financial Studies 3, 773-816. DOI: 10.1093/rfs/8.3.773.

Hogan, W., Warren J., 1974. Toward the development of an equilibrium capitalmarket model based on semivariance, Journal of Financial and Quantitative Analysis 9, 1-11. DOI: 10.2307/2329964.

Kahneman, D., Tversky, A., 1979. Prospect Theory: An Analysis of Decision under Risk, Econometrica 2, 263-291. DOI: 10.2307/1914185.

Lintner, J., 1965. The valuation of risk assets and the selection of risky investments in stock portfolios and capital budgets, Review of Economics and Statistics 1, 13-37. DOI: 10.2307/1924119.

Pukthuanthing, K., Roll, R., 2009. Global market integration: An alternative measure and its application, Journal of Financial Economics 2, 214-232. DOI: 10.1016/j.jfineco.2008.12.004.

Roy, A., 1952. Safety-First and the Holdings of Assets, Econometrica 3, 431-49. DOI: $10.2307 / 1907413$.

Sharpe, W. F., 1964. Capital asset prices: a theory of market equilibrium under conditions of risk, Journal of Finance 3, 425-442. DOI: 10.1111/j.15406261.1964.tb02865.x. 


\section{Appendix 1: Heading of the appendix}

Tab. A.1 Emerging Markets Returns

\begin{tabular}{|c|c|c|c|c|c|}
\hline Country & $\mu$ & $\sigma_{i}$ & $\beta$ & $\sum_{i}$ & $\beta^{D}$ \\
\hline India & $1.06 \%$ & 0.08 & 1.23 & 0.08 & 0.96 \\
\hline China & $0.82 \%$ & 0.08 & 1.20 & 0.08 & 0.92 \\
\hline Colombia & $1.94 \%$ & 0.09 & 0.95 & 0.09 & 1.05 \\
\hline Russia & $1.28 \%$ & 0.10 & 1.50 & 0.11 & 1.20 \\
\hline Czech Republic & $1.28 \%$ & 0.08 & 1.12 & 0.08 & 0.90 \\
\hline South Korea & $0.96 \%$ & 0.08 & 1.38 & 0.08 & 0.92 \\
\hline Brazil & $1.28 \%$ & 0.10 & 0.03 & 0.10 & 1.20 \\
\hline Indonesia & $1.64 \%$ & 0.09 & 1.08 & 0.10 & 1.05 \\
\hline Mexico & $0.89 \%$ & 0.07 & 1.18 & 0.07 & 0.81 \\
\hline South Africa & $1.07 \%$ & 0.08 & 1.19 & 0.08 & 0.92 \\
\hline Pakistan & $1.60 \%$ & 0.09 & 0.47 & 0.09 & 0.97 \\
\hline Morocco & $0.71 \%$ & 0.06 & 0.41 & 0.05 & 0.59 \\
\hline Egypt & $1.32 \%$ & 0.10 & 1.00 & 0.10 & 1.08 \\
\hline Chile & $0.81 \%$ & 0.06 & 0.90 & 0.06 & 0.69 \\
\hline Argentina & $1.78 \%$ & 0.12 & 1.17 & 0.11 & 1.25 \\
\hline Turkey & $0.95 \%$ & 0.13 & 1.83 & 0.13 & 1.55 \\
\hline Thailand & $1.35 \%$ & 0.08 & 1.09 & 0.08 & 0.93 \\
\hline Poland & $0.72 \%$ & 0.09 & 1.53 & 0.09 & 1.04 \\
\hline Peru & $1.66 \%$ & 0.08 & 0.99 & 0.09 & 0.95 \\
\hline Jordan & $0.53 \%$ & 0.06 & 0.29 & 0.05 & 0.59 \\
\hline Israel & $0.39 \%$ & 0.06 & 0.92 & 0.07 & 0.72 \\
\hline Hungary & $1.04 \%$ & 0.10 & 1.60 & 0.10 & 1.14 \\
\hline Taiwan & $0.48 \%$ & 0.07 & 1.08 & 0.07 & 0.83 \\
\hline Sri Lanka & $1.35 \%$ & 0.10 & 0.56 & 0.08 & 0.87 \\
\hline Philippines & $1.00 \%$ & 0.07 & 0.77 & 0.07 & 0.81 \\
\hline Malaysia & $0.62 \%$ & 0.05 & 0.66 & 0.06 & 0.63 \\
\hline
\end{tabular}

Source: Eikon + author's computations. 
Ajrapetova, T.: Cross-section of asset returns: Emerging Markets and Market Integration.

Tab. A.2 Developed Market Returns

\begin{tabular}{|c|c|c|c|c|c|}
\hline Country & $\mu$ & $\sigma_{i}$ & $\beta$ & $\sum_{i}$ & $\beta^{D}$ \\
\hline Austria & $0.59 \%$ & 0.08 & 1.330 & 0.062 & 1.070 \\
\hline Australia & $0.93 \%$ & 0.06 & 1.177 & 0.046 & 0.851 \\
\hline Belgium & $0.46 \%$ & 0.06 & 1.154 & 0.055 & 0.937 \\
\hline Denmark & $0.99 \%$ & 0.06 & 1.070 & 0.045 & 0.855 \\
\hline Finland & $0.69 \%$ & 0.09 & 1.530 & 0.063 & 0.960 \\
\hline France & $0.51 \%$ & 0.06 & 1.243 & 0.043 & 0.900 \\
\hline Germany & $0.59 \%$ & 0.07 & 1.417 & 0.050 & 1.029 \\
\hline Greece & $-0.68 \%$ & 0.11 & 1.548 & 0.081 & 1.147 \\
\hline Hong Kong & $0.86 \%$ & 0.06 & 1.053 & 0.043 & 0.771 \\
\hline Ireland & $0.04 \%$ & 0.07 & 1.122 & 0.052 & 0.874 \\
\hline Italy & $0.24 \%$ & 0.07 & 1.237 & 0.047 & 0.848 \\
\hline Japan & $0.36 \%$ & 0.05 & 0.767 & 0.031 & 0.560 \\
\hline Netherlands & $0.54 \%$ & 0.06 & 1.229 & 0.047 & 0.942 \\
\hline New Zealand & $0.87 \%$ & 0.06 & 0.985 & 0.045 & 0.706 \\
\hline Norway & $0.95 \%$ & 0.08 & 1.422 & 0.057 & 1.037 \\
\hline Canada & $0.85 \%$ & 0.06 & 1.128 & 0.043 & 0.825 \\
\hline Portugal & $0.04 \%$ & 0.07 & 1.022 & 0.045 & 0.694 \\
\hline Singapore & $0.85 \%$ & 0.07 & 1.142 & 0.051 & 0.880 \\
\hline Spain & $0.55 \%$ & 0.07 & 1.265 & 0.048 & 0.871 \\
\hline Sweden & $0.88 \%$ & 0.08 & 1.465 & 0.053 & 1.077 \\
\hline Switzerland & $0.55 \%$ & 0.05 & 0.850 & 0.033 & 0.651 \\
\hline UK & $0.36 \%$ & 0.05 & 0.986 & 0.033 & 0.707 \\
\hline USA & $0.50 \%$ & 0.04 & 0.937 & 0.032 & 0.703 \\
\hline
\end{tabular}

Source: Eikon + author's computations. 
Tab. A.3 Correlation Matrix Emerging Markets

\begin{tabular}{|c|c|c|c|c|c|c|}
\hline \multicolumn{7}{|c|}{ Correlations } \\
\hline & & Mean & $\begin{array}{l}\text { Standard } \\
\text { Deviation }\end{array}$ & Beta & $\begin{array}{c}\text { Semi- } \\
\text { deviation }\end{array}$ & $\begin{array}{l}\text { Downside } \\
\text { Beta }\end{array}$ \\
\hline \multirow{3}{*}{ Mean } & $\begin{array}{l}\text { Pearson } \\
\text { Correlation }\end{array}$ & 1 & $0.567^{* *}$ & 0.003 & $0.537^{* *}$ & $0.514^{* *}$ \\
\hline & Sig. (2-tailed) & & 0.003 & 0.987 & 0.005 & 0.007 \\
\hline & $\mathrm{N}$ & 26 & 26 & 26 & 26 & 26 \\
\hline \multirow{3}{*}{$\begin{array}{l}\text { Standard } \\
\text { Deviation }\end{array}$} & $\begin{array}{l}\text { Pearson } \\
\text { Correlation }\end{array}$ & $0.567^{* *}$ & 1 & $0.407^{*}$ & $0.953^{* *}$ & $0.947^{* *}$ \\
\hline & Sig. (2-tailed) & 0.003 & & 0.039 & 0.000 & 0.000 \\
\hline & $\mathrm{N}$ & 26 & 26 & 26 & 26 & 26 \\
\hline \multirow{3}{*}{ Beta } & $\begin{array}{l}\text { Pearson } \\
\text { Correlation }\end{array}$ & 0.003 & $0.407^{*}$ & 1 & $0.507^{* *}$ & $0.523^{* *}$ \\
\hline & Sig. (2-tailed) & 0.987 & 0.039 & & 0.008 & 0.006 \\
\hline & $\mathrm{N}$ & 26 & 26 & 26 & 26 & 26 \\
\hline \multirow{3}{*}{ Semi-deviation } & $\begin{array}{l}\text { Pearson } \\
\text { Correlation }\end{array}$ & $0.537^{* *}$ & $0.953^{* *}$ & $0.507^{* *}$ & 1 & $0.992^{* *}$ \\
\hline & Sig. (2-tailed) & 0.005 & 0.000 & 0.008 & & 0.000 \\
\hline & $\mathrm{N}$ & 26 & 26 & 26 & 26 & 26 \\
\hline \multirow{3}{*}{ Downside Beta } & $\begin{array}{l}\text { Pearson } \\
\text { Correlation }\end{array}$ & $0.514^{* *}$ & $0.947^{* *}$ & $0.523^{* *}$ & $0.992^{* *}$ & 1 \\
\hline & Sig. (2-tailed) & 0.007 & 0.000 & 0.006 & 0.000 & \\
\hline & $\mathrm{N}$ & 26 & 26 & 26 & 26 & 26 \\
\hline
\end{tabular}

Note: **. Correlation is significant at the 0.01 level (2-tailed). *. Correlation is significant at the 0.05 level (2-tailed).

Source: Eikon + author's computations. 
Ajrapetova, T.: Cross-section of asset returns: Emerging Markets and Market Integration.

Tab. A.4 Correlation matrix Developed Market

\begin{tabular}{|c|c|c|c|c|c|c|}
\hline \multicolumn{7}{|c|}{ Correlations } \\
\hline & & Mean & $\begin{array}{l}\text { Standard } \\
\text { Deviation }\end{array}$ & Beta & $\begin{array}{c}\text { Semi- } \\
\text { deviation }\end{array}$ & $\begin{array}{c}\text { Downside } \\
\text { Beta }\end{array}$ \\
\hline \multirow{3}{*}{ Mean } & $\begin{array}{l}\text { Pearson } \\
\text { Correlation }\end{array}$ & 1 & 0.136 & 0.272 & 0.203 & 0.312 \\
\hline & Sig. (2-tailed) & & 0.546 & 0.221 & 0.364 & 0.158 \\
\hline & $\mathrm{N}$ & 22 & 22 & 22 & 22 & 22 \\
\hline \multirow{3}{*}{$\begin{array}{l}\text { Standard } \\
\text { Deviation }\end{array}$} & $\begin{array}{l}\text { Pearson } \\
\text { Correlation }\end{array}$ & 0.136 & 1 & $0.841^{* *}$ & $0.902^{* *}$ & $0.741^{* *}$ \\
\hline & Sig. (2-tailed) & 0.546 & & 0.000 & 0.000 & 0.000 \\
\hline & $\mathrm{N}$ & 22 & 22 & 22 & 22 & 22 \\
\hline \multirow{3}{*}{ Beta } & $\begin{array}{l}\text { Pearson } \\
\text { Correlation }\end{array}$ & 0.272 & $0.841^{* *}$ & 1 & $0.835^{* *}$ & $0.924^{* *}$ \\
\hline & Sig. (2-tailed) & 0.221 & 0.000 & & 0.000 & 0.000 \\
\hline & $\mathrm{N}$ & 22 & 22 & 22 & 22 & 22 \\
\hline \multirow{3}{*}{ Semi-deviation } & $\begin{array}{l}\text { Pearson } \\
\text { Correlation }\end{array}$ & 0.203 & $0.902^{* *}$ & $0.835^{* *}$ & 1 & $0.845^{* *}$ \\
\hline & Sig. (2-tailed) & 0.364 & 0.000 & 0.000 & & 0.000 \\
\hline & $\mathrm{N}$ & 22 & 22 & 22 & 22 & 22 \\
\hline \multirow{3}{*}{ Downside Beta } & $\begin{array}{l}\text { Pearson } \\
\text { Correlation }\end{array}$ & 0.312 & $0.741^{* *}$ & $0.924^{* *}$ & $0.845^{* *}$ & 1 \\
\hline & Sig. (2-tailed) & 0.158 & 0.000 & 0.000 & 0.000 & \\
\hline & $\mathrm{N}$ & 22 & 22 & 22 & 22 & 22 \\
\hline
\end{tabular}

Note: $* *$. Correlation is significant at the 0.01 level (2-tailed).

Source: Eikon + author's computations. 